Research Article

\title{
Computational Fluid Dynamics Study of the Effects of Drill Cuttings on the Open Channel Flow
}

\author{
Prasanna Welahettige ${ }^{D}{ }^{1}$ Christian Berg, ${ }^{1,2}$ Joachim Lundberg, ${ }^{1}$ Bernt Lie, ${ }^{1}$ \\ and Knut Vaagsaether $\left(\mathbb{D}^{1}\right.$ \\ ${ }^{1}$ Department of Process, Energy and Environmental Technology, University of South-Eastern Norway, Porsgrunn 3918, Norway \\ ${ }^{2}$ Kelda Drilling Controls, Porsgrunn 3933, Norway
}

Correspondence should be addressed to Knut Vaagsaether; knut.vagsather@usn.no

Received 23 April 2019; Revised 18 July 2019; Accepted 31 July 2019; Published 22 August 2019

Academic Editor: Sébastien Déon

Copyright (C) 2019 Prasanna Welahettige et al. This is an open access article distributed under the Creative Commons Attribution License, which permits unrestricted use, distribution, and reproduction in any medium, provided the original work is properly cited.

\begin{abstract}
A three-dimensional computational fluid dynamics (CFD) study was carried out for drilling fluid flow with drill cuttings in open channels. The flow is similar to the return flow when drilling, stream containing drilling fluid, and drill cuttings. The computational model is under the framework of the Eulerian multifluid volume of the fluid model. The Herschel-Bulkley rheological model was used to describe the non-Newtonian rheology of the drilling fluid, and the computational model was validated with experimental results for two-phase flow in the literature. The effect of flow depth and flow velocity in an open channel was studied for drill cutting size of up to $5 \mathrm{~mm}$ and for a solid volume fraction of up to $10 \%$. For constant cross section and short open channels, the effect of drill cuttings on flow depth and mean velocity was found to be small for particle sizes less than $5 \mathrm{~mm}$ and solid volume fractions less than $10 \%$. High momentum force in the downward direction can carry the solid-liquid mixture at higher velocities than a lower density mixture. Higher inclination angles mean that the gravity effect upon the flow direction is more significant than the particle friction for short channels.
\end{abstract}

\section{Introduction}

Open Venturi channel flow measurement might be an alternative to expensive Coriolis flow meters in measuring well return flows while drilling [1]. It can also be an alternative in conventional drilling when there is no choke and where flow is "always" open channel, Coriolis therefore not being an option. The open channel is located at the well return line in the topside of the rig (see Figure 1). Identifying the effect of drill cuttings on open channel flow is, however, a challenge.

Several studies have been carried out on sediment flow in an open channel. The particle sizes in these studies were, however, in the $1 \mu \mathrm{m}$ to $500 \mu \mathrm{m}$ range [2-5]. Studies of pipe flow drill cutting transport have also been carried out for various particle sizes and volume fractions $[6,7]$. Ofei et al. [8] used the Eulerian-Eulerian model for drill cutting simulation of the horizontal wellbore. The annular pressure losses increase with increase in annular fluid velocity. Drill mud has higher pressure losses compared to water, and the mud has better carrying capacity, especially at smaller diameter ratios of the annulus. According to Epelle and Gerogiorgis [9], the higher pressure losses are due to higher drag by the fluid on particles and frictional effects. Whirling motion increases the particle-particle and particle-wall collisions; this is also responsible for increase in pressure drop in the annulus. Heydari et al. [10] studied CFD simulation on cuttings transport phenomena in various annuluses. They used the Herschel-Bulkley model as the rheological model, the Reynolds stress model as the turbulence model, and the Wen and Yu drag model as the drag model. Near the wall of horizontal annulus flow, cuttings do not flow easily, and velocity becomes almost zero. Pang et al. [11] studied three regions of cuttings in a horizontal annulus flow: a fixed bed region, a moving bed region, and a suspension region. The cuttings suspension region contributes as a major cuttings transport method in a horizontal 


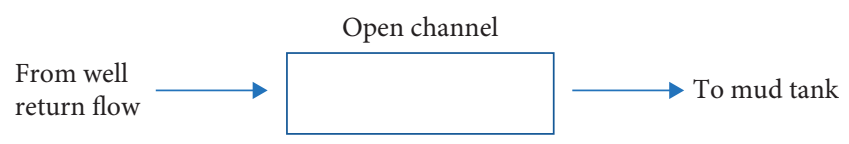

FIgURE 1: The open channel is located between the choke valve and the mud tank.

annulus. The height of the cuttings bed decreases with increase in effective viscosity of the drilling fluid in annulus flow [12]. Increase in effective viscosity can reduce the cuttings bed area [13].

According to the Muste et al.'s [4] experimental study on water-particle flow in open channel flow, bulk velocity of flow is reduced as particle concentration increases and suspended particles affect turbulence mechanisms over the inner region of the flow. Jha and Bombardelli [2] developed a two-phase model for the transport of nonuniform suspended sediment in an open channel (water and sediment). The influence of particle size is significant for the mean velocity. Increase in the particle concentration in the bed only affects the turbulent kinetic energy [14]. A laminar flow occurs in open channel slurry flows if the yield stress is significantly high. Coarse particle settling might affect the height of vertical flow depth [5]. The Sanders et al. [15] and Spelay's [5] experimental studies involve coarse sand slurries in an open channel flow. Treinen [16] and Talmon et al. [17] studied shear settling in laminar open channel flow numerically.

Drill cuttings have a size range from clay-sized particles to coarse gravel, $2 \mu \mathrm{m}$ to more than $30 \mathrm{~mm}$ [18], the highest concentration of particle size in well drilling being $4 \mathrm{~mm}$. According to the literature, the volumetric fraction of cuttings is normally less than $5 \%$ for trouble-free annulus operations $[19,20]$. There has, however, to the best of our knowledge, not been published much on drill cuttings flow in open channel flow. This study therefore aims to contribute to the lack of knowledge on the cuttings effect upon open channel flow depth and velocity profile. Non-Newtonian drilling fluid flow with drill cuttings was studied in this paper using CFD simulations, the CFD model being validated using the experiment results from the literature. The primary objective of the study was to identify the effect of drill cuttings and particle settling on open channel flow depth.

\section{CFD Model}

An Eulerian multifluid volume of the fluid model (multifluid VOF) was used for the simulation of the granular particles. Each phase is a continuous phase. Three phases are considered in this study. The governing continuity equation for the $q^{\text {th }}$ phase $(g, l$, and $s$ phases, respectively, air, drilling fluid, and drill cuttings) is

$$
\frac{\partial \alpha_{q} \rho_{q}}{\partial t}+\nabla \cdot\left(\alpha_{q} \rho_{q} \vec{u}_{q}\right)=0 .
$$

There are three equations similar to equation (1) for each phase. There is no net mass transfer between phases. The total volume fraction is equal to unity, $\alpha_{g}+\alpha_{l}+\alpha_{s}=1$. The momentum conservation equation for the $q^{\text {th }}$ phase $[7,21,22]$ is

$$
\begin{aligned}
& \frac{\partial \alpha_{q} \rho_{q} \vec{u}_{q}}{\partial t}+\nabla \cdot\left(\alpha_{q} \rho_{q} \vec{u}_{q} \vec{u}_{q}\right)=-\alpha_{q} \nabla P+\nabla \cdot \overline{\bar{\tau}}_{q} \\
& +\alpha_{p} \rho_{q} \vec{g}+\sum_{i=1}^{2} \beta_{q i}\left(\vec{u}_{i}-u_{q}\right)+\left(\vec{F}_{\mathrm{lift}, q}+\vec{F}_{\mathrm{Vm}, q}\right) .
\end{aligned}
$$

There are, one for each phase, three momentum equations from equation (2). Densities are constant. The effective viscosity of the drilling fluid was calculated using the Herschel-Bulkley model. Drill cuttings are considered to be spherical, monotonous (same size and shape), granular, and solid particles. Several interactions can occur in open channel flow: air-drilling fluid, drilling fluid-drill cuttings, drill cuttings-drill cuttings, wall-drill cuttings, wall-drilling fluid, drilling fluid-drilling fluid, and air-drill cuttings. Here, air-drill cuttings interaction can be neglected by assuming that the particles are submerged in the drilling fluid. The gasliquid interface drag was calculated using the Schiller and Naumann drag model $[23,24]$. Solid-liquid interface drag was calculated using the Wen and Yu drag model [25]. Lift force and virtual mass forces were neglected for the gas phase due to the secondary phase densities being more significant than the gas density [26]. The ANSYS Fluent 18.2 commercial CFD tool was used for the simulations.

Figure 2 shows the multifluid VOF method computing cycle in transient condition for two-phase flow. Here, the discretized momentum equation is solved using a guessed pressure field in the initial step (the previous iteration result being used after this), to yield the velocity field. The pressure correction terms can be found from the calculated velocity field and the continuity equation. The corrected pressure and velocity fields can be calculated from the calculated pressure correction and velocity correction terms. An assumption in the SIMPLE algorithm is that the velocity corrections for the neighboring cells are omitted in each iteration cycle. However, the omission terms do not affect the final solution because the correction factors become zero in a converged result [27].

\section{Simulation Parameters}

A rectangular channel was used for the 3D CFD simulations. The channel length was $1 \mathrm{~m}$, width $0.3 \mathrm{~m}$, and height $0.2 \mathrm{~m}$. The mesh had 0.7 million structured hexahedral elements including inflation near the walls (see Figure 3).

The inflation layers were added for accurately capturing the flow effects near the walls. The average mesh size was $25 \mathrm{~mm}$, which is 5 times larger than the largest particle size used in the study. This avoids particles spanning the many fluid cells. Edge sizing was implemented to improve the resolution of the mesh. The mesh had low skewness $(<0.8)$ and high orthogonality $(>0.9)$. To optimize the grid sizes until the results become independent of grid size, a grid independence study was conducted. The inlet drill cutting mass flow rate was $1.12599 \mathrm{~kg} / \mathrm{s}$. The outlet drill cutting mass flow rate was monitored for different mesh sizes in the test. The results were taken after reaching the steady state. Table 1 shows the mesh specification for different meshes. Figure 4 shows a solid mass flow rate comparison for the different 


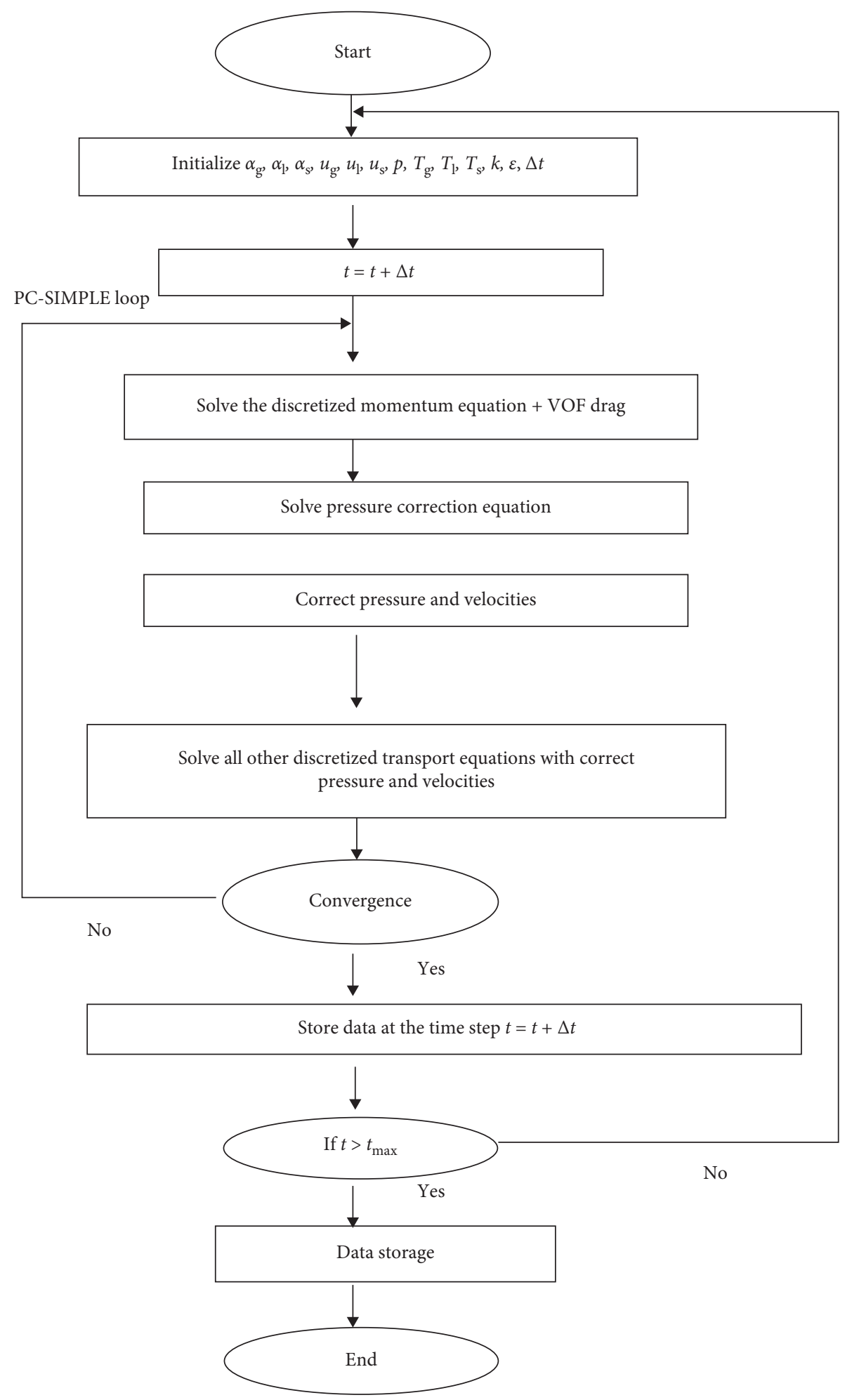

FIGURE 2: Computing cycle of transient multifluid VOF model for three-phase flow.

meshes. Mesh 3 and Mesh 4 give good mass balance at steady-state condition. Mesh 3 was used for further studies because it has comparatively fewer numbers of elements than Mesh 4.

The drilling fluid used in this study was taken from Kelessidis et al.' study [28]. The fluid has a high yield stress, and the other properties are given in Table 2. Drill cutting and drilling fluid enter the channel as a mixture at the same inlet velocity.

Based on the maximum Courant number, the time step is refined near the free surface in VOF calculations. The maximum allowed Courant number is 0.25 in this study. The 


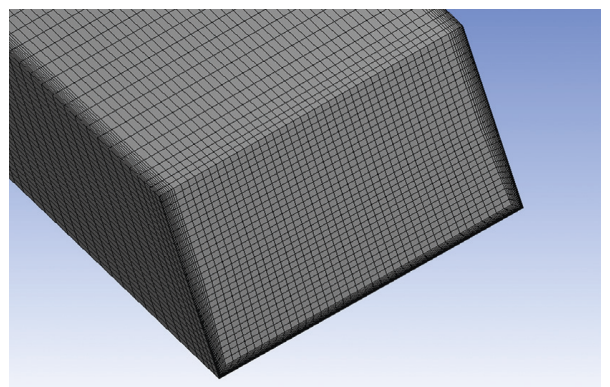

Figure 3: 3D section of meshed open channel geometry. The rectangular channel height, width, and length are, respectively, $0.2 \mathrm{~m}, 0.3 \mathrm{~m}$, and $1 \mathrm{~m}$.

TABle 1: Different mesh for mesh independency check.

\begin{tabular}{lcccccc}
\hline & Mesh 1 & Mesh 2 & Mesh 3 & Mesh 4 & Mesh 5 & Mesh 6 \\
\hline Hexahedral cells & 0.342 & 0.487 & 0.7 & 1.02 & 1.35 & 1.93 \\
\hline
\end{tabular}

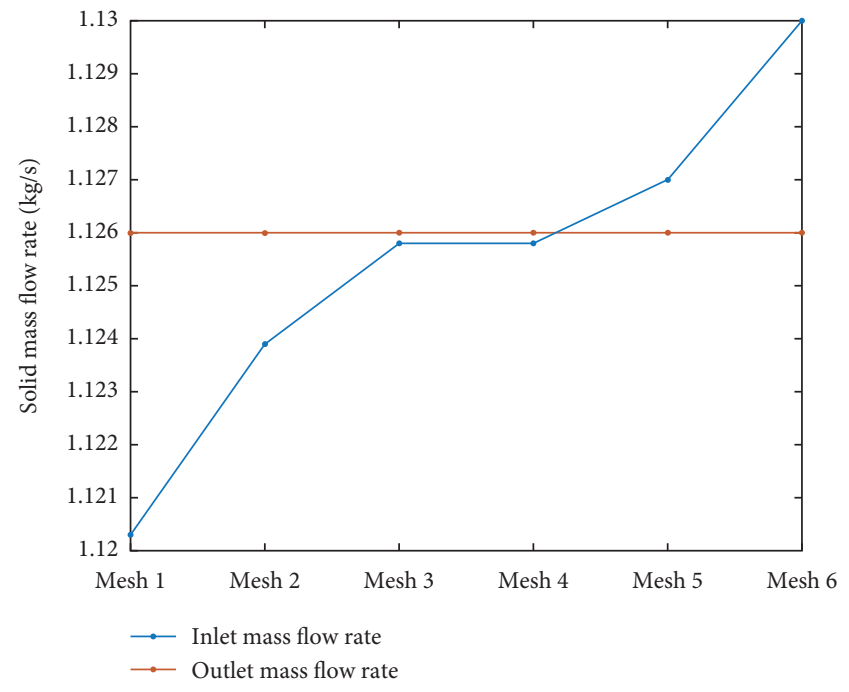

Figure 4: Solid mass flow rate comparison for different meshes. The number of elements in each mesh is given in Table 1.

global Courant number depends on the mesh size, velocity field, and time step size used for the transport equations. Volume fraction values are computed at the previous time step in the explicit approach of the multifluid VOF model, and the standard finite-difference interpolation scheme is used in ANSYS Fluent [26]. The simulation carried out in the transient condition and the time step was maintained at less than $0.001 \mathrm{~s}$ for two-phase flow and $0.0001 \mathrm{~s}$ for three-phase flow, to achieve converged results. These time steps allow keeping the global Courant number less than two. The flow time is $20 \mathrm{~s}$ in each simulation; in this condition, the fluid domain reached the steady state. The steady-state condition was monitored after a constant solid-phase flow rate was reached at the outlet. The no-slip condition applies to the wall-fluid and wall-particle. The pressure field is assumed to be shared by all three phases, this being in proportion to their volume fraction [22]. The solid particle maximum packing fraction is 0.63 for the spherical shape. Particleparticle and wall-particle restitution coefficients were, respectively, 0.9 and 0.09 [6]. The inlet was considered as a velocity inlet. The inlet velocities are constants for all three phases. Air volume flow rate at the inlet became zero for the cases. The outlet and top boundaries are considered as pressure outlets. The pressure outlets are at atmospheric pressure. Air is the primary phase, and drilling fluid and drill cuttings are considered to be the secondary phases. The gas-liquid surface tension coefficient was set to $0.072 \mathrm{~N} / \mathrm{m}$ due to the water-based drilling fluid and slurries considered in this study. The spatial discretization schemes for gradient, momentum, volume fraction, turbulent kinetic energy, and turbulent dissipation rates are, respectively, least square cell-based, first-order upwind, compressive, second-order upwind, and second-order upwind. The Eulerian multifluid VOF model and the sharpdisperse interface modeling method were used to describe the flow of each phase. The standard $k-\varepsilon$ model is used to model turbulence using the second-order upwind scheme. The phase-coupled semi-implicit method for pressurelinked equations (SIMPLE) algorithm solves the pressurevelocity coupling. Transient formulation is based on the first-order implicit scheme.

The computational method is due to the lack of experimental results for heavy particle non-Newtonian open channel flow and high computation cost, validated for an experimental case of two-phase non-Newtonian flow in open channel. Haldenwang's [29] experiments with the flow of Kaolin slurry in an open channel were used to validate the two-phase model. The two phases in these experiments were slurry and air above the free surface. The slurry contained small solid Kaolin particles. The experiments were conducted in a rectangular $10 \mathrm{~m}$ long and $0.3 \mathrm{~m}$ wide channel. The rheology of the Kaolin slurry was described using the Herschel-Bulkley model. 
TABLe 2: Simulation flow parameters. Case 1 is used in this study. Case 2 is used for model validation.

\begin{tabular}{lcc}
\hline & Case 1 & Case 2 \\
\hline Fluid and solid & Water-bentonite suspension [28] & 10\% v/v Kaolin slurry [29] \\
Fluid density $\left(\mathrm{kg} / \mathrm{m}^{3}\right)$ & 1165 & 1303 \\
Particle density $\left(\mathrm{kg} / \mathrm{m}^{3}\right)$ & 2650 & - \\
Mean particle diameter $(\mathrm{mm})$ & 5,1 & - \\
Inlet solid volume fraction (\%) & 5,10 & 0.567 \\
Inlet velocity $(\mathrm{m} / \mathrm{s})$ & 1 & Rectangular \\
Shape of the channel & Rectangular & 2 \\
Channel inclination & 3 & 21.311 \\
Yield stress $\tau_{y}(\mathrm{~Pa})$ & 11.3025 & 0.524 \\
Flow consistency index $k\left(\mathrm{~Pa} \cdot \mathrm{s}^{n}\right)$ & 5.9115 & 0.468 \\
Flow behavior index $n$ & 0.2645 & \\
\hline
\end{tabular}

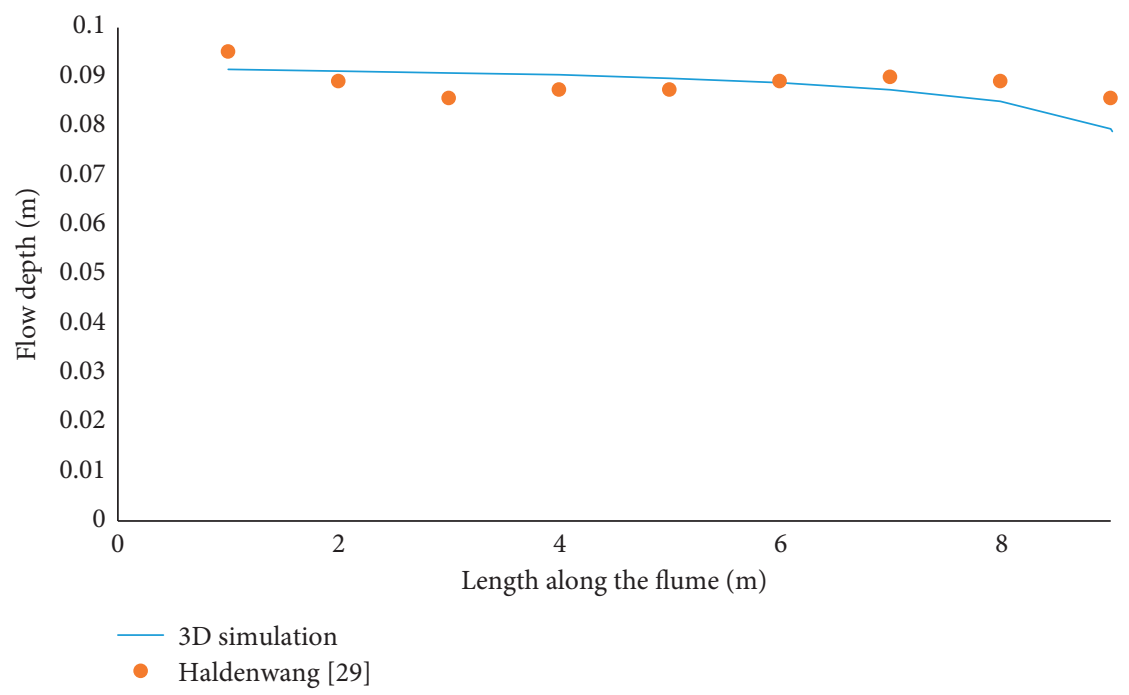

(a)

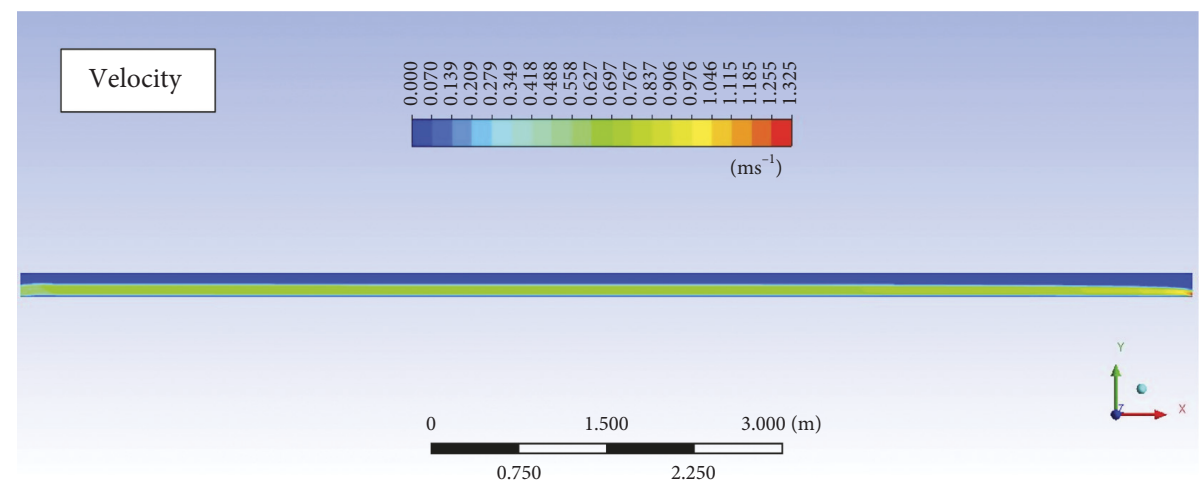

(b)

Figure 5: Case 2: (a) a comparison between the 3D CFD result and the Haldenwang [29] experimental results for flow depth along the channel axis at steady state. The channel length is $10 \mathrm{~m}$, and the width is $0.3 \mathrm{~m}$. The fluid properties of Case 2 are given in Table 2 . (b) Velocity profile, the flow direction is left to right.

\section{Results and Discussion}

\subsection{D CFD Results Validation Using Literature Experimental} Results. The two-phase CFD model was validated using the experimental results published by Haldenwang [29]. A comparison between the 3D CFD simulation and the Haldenwang [29] experiment results is shown in Figure 5. Flow depth was measured after the steady state, at flow time $249 \mathrm{~s}$ in the simulation. The free surface was captured from the VOF model. The fluid used in the experiments contained $10 \%$ Kaolin particles, ranging from $0.001 \mathrm{~mm}$ to $0.01 \mathrm{~mm}$. The 3D simulation, however, considered the average fluid density that is based on the volume fraction of Kaolin and water. In the experiment, fluid enters the channel from a 
buffer tank. A rectangular inlet geometry was used in the simulation. There, therefore, may be a discrepancy between the inlet conditions. The accuracy of the experimental result is $5 \%$, and the simulated result accuracy is $6 \%$ for the experimental results. The $3 \mathrm{D}$ CFD result is therefore within the accuracy limit.

Open channel length should be considerably longer if a fully developed flow profile is to be achieved [5, 29]. A 3D CFD simulation of two-phase or three-phase open channel flow takes many months of CPU time to run based on a 16core $2.4 \mathrm{GHz}$ Intel (R) CPU processor in a machine with $32 \mathrm{~GB}$ of RAM [6]. A short channel (length $1 \mathrm{~m}$ ) was therefore used in this study.

4.2. Effect of Drill Cutting on the Open Channel Flow Depth. Figure 6 shows flow depths along the channel for different particle sizes and different volume fractions. The two 5\% solid volume fraction cases have two different particle sizes, $5 \mathrm{~mm}$ and $1 \mathrm{~mm}$. Flow depth variation for these two cases is, however, negligible. This is furthermore proved by the $10 \%$ volume fraction cases. The effect of drill cutting size on flow depth is not significant. The CFD results of Amanna and Khorsand Movaghar [7] for cuttings transport around a drill pipe also proved that cutting size affects cuttings transport less than the other parameters. The cases of $5 \mathrm{~mm}$ particle sizes with $5 \%$ and $10 \%$ volume fractions show flow depth differing between the two cases. Particle volume fraction can have a considerable impact on flow depth. Flow depth changes by $2.5 \%$ when the solid volume fraction in a dilute phase is doubled. The difference in total particle volume between the $1 \mathrm{~mm}$ and $5 \mathrm{~mm}$ cases is small due to the fewer number of particles in the dilute phase. The increase in particle friction due to the rise of the total particle volume is also small, and energy loss is negligible. Higher volume fraction gives a lower level because higher concentration acts as a higher net density. Thus, the higher density and approximately the same friction will yield a lower level.

In all cases, the flow depth reduces along the channel length, which is due to the increase in velocity in the gravity flow. The highest cutting concentration gives the lowest flow depth due to the largest momentum.

4.3. Mean Streamwise Velocity Distribution. Streamwise velocity with particles and without particles is shown in Figure 7 for the same volume flow rate. Fluids with particle flow have a higher velocity than the no-solid case due to the higher momentum of the total mass flow rate. The average velocity difference between with particle and without particle is $2-3 \%$. The slip velocity is very small, with the average value being $0.001 \mathrm{~m} / \mathrm{s}$. This result indicates that the impact of the mean flow velocity of the drill cuttings is very small. The local slip velocity can be large in the outer region of the flow for a fully developed flow [3].

4.4. Particle Settling. Very high wall friction applies to particle flow because of higher particle concentrations ( $\approx 40 \%$ ) on the bottom. Particle settling on the bottom of the

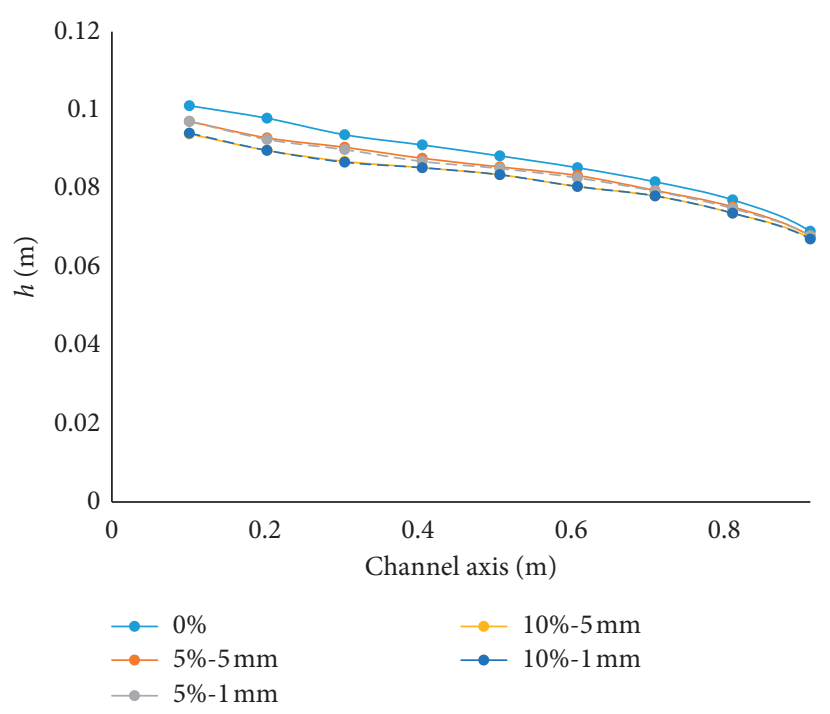

Figure 6: 3D CFD results of flow depth along the channel for different drill cuttings sizes and volume fraction at steady state. The inlet velocity is $0.5665 \mathrm{~m} / \mathrm{s}$ for all cases, and the total inlet volume flow rate value is equal for each case.

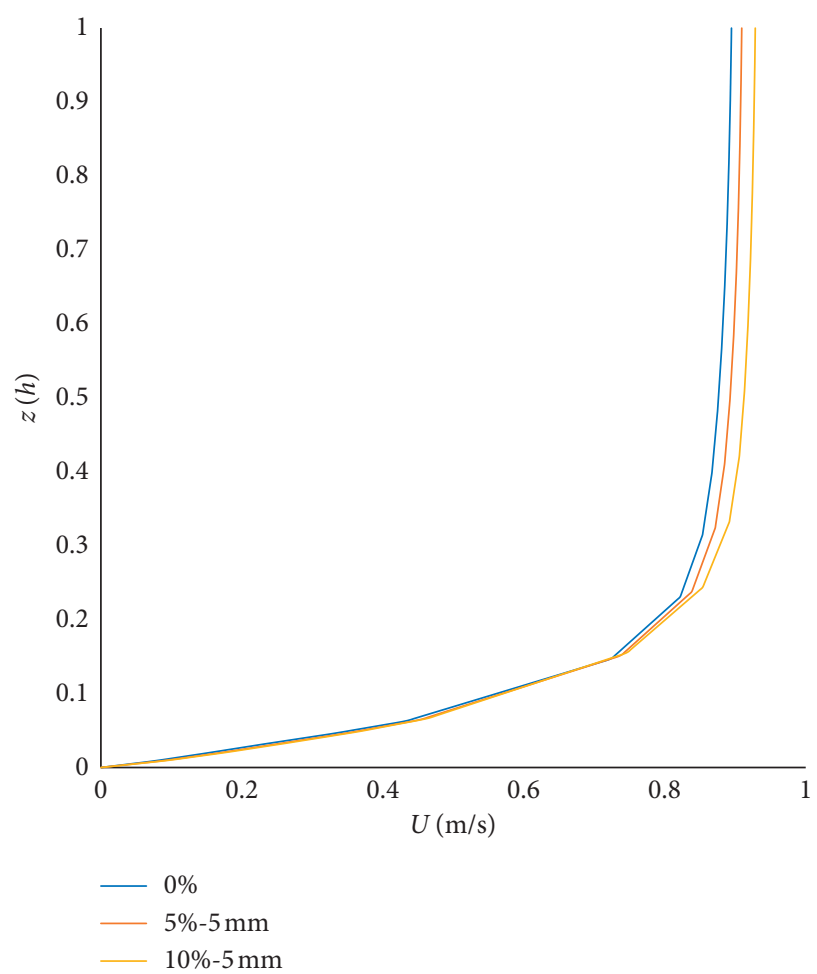

FIGURE 7: Steamwise velocity distribution with particle and without particle for the same inlet volume flow rate. The inlet velocity is $0.5665 \mathrm{~m} / \mathrm{s}$. The velocity is measured $0.7 \mathrm{~m}$ to the downstream from inlet of the channel.

open channels might lead to the simulations diverging due to the increase in turbulence. This is the main difficulty of modeling long open channel three-phase flow. This difficulty can be minimized with properly tuned under-relaxation factors and correctly chosen spatial discretization schemes. A converged result can be achieved when the time step 


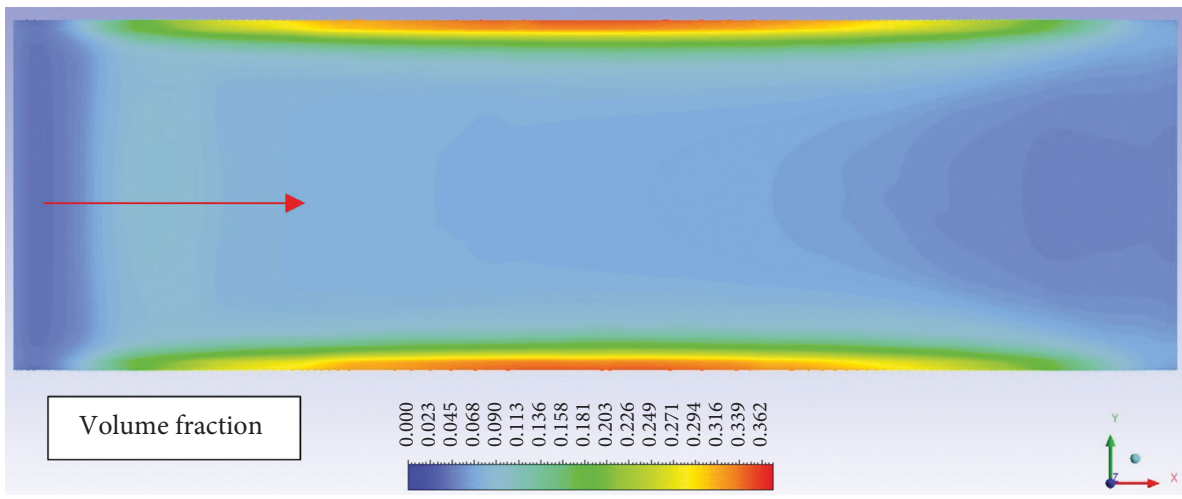

(a)

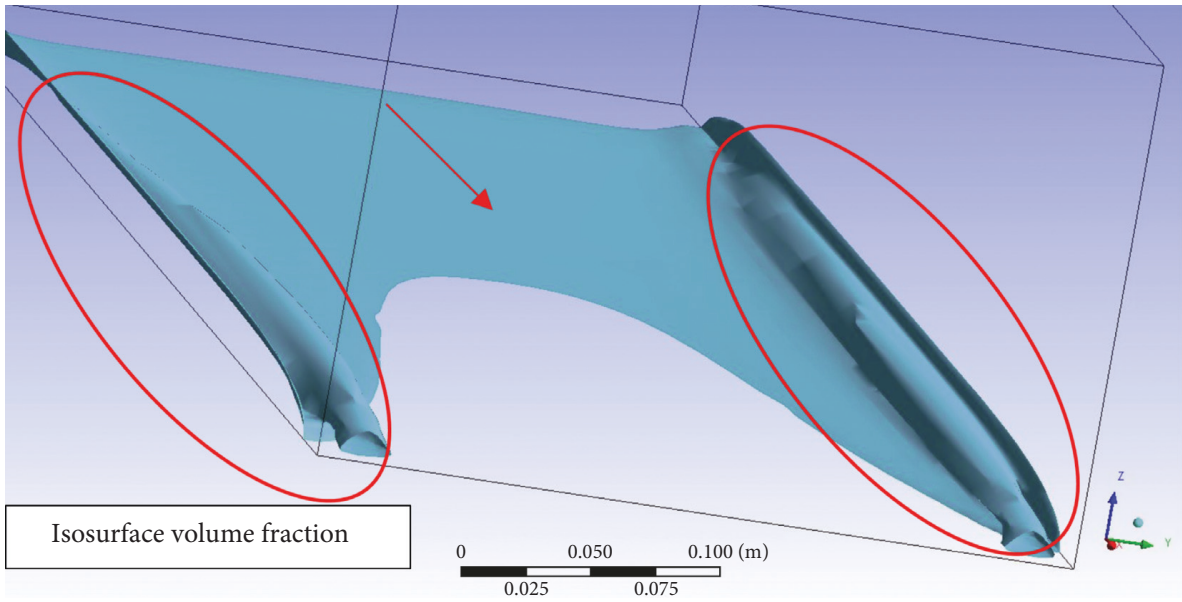

(b)

Figure 8: Particle settling bottom wall, the flow direction indicates by the arrow. Drill cutting size is $5 \mathrm{~mm}$ and inlet volume fraction is 0.05 . (a) The solid volume fraction of drill cuttings on the bottom of the open channel at steady state, $x y$ plane. (b) Isosurface of solid volume fraction at 0.08 .

reaches a minimum $\left(<10^{-6} \mathrm{~s}\right)$. This, however, requires a computational time that is unrealistic. The channel used in this study is $1 \mathrm{~m}$ long with a low solid concentration. The short channel helped to reduce the computational time by reducing the number of computational cells. The settling distance is greater than the channel length. Particle settling is therefore considerably smaller in the channel used in this study than a long channel. Therefore, the results from this study mainly apply on to not fully developed flow. Figure 8 shows the particle volume fraction on the bottom wall at the steady state. The highest particle settling is near the sidewall and reaches $40 \%$ solid volume fraction. Due to sidewall friction, particles have lower velocities near the sidewall. Particle settling is, however, conceded to be small at the inlet and outlet of the channel due to the higher flow velocity carrying particles without these settling. At the bottom wall, particle settling is lower in the middle compared to near the sidewalls. This is due to high velocity at the middle compared to at the edges. Channel flow does not reach a fully developed condition. According to Kiger and Pan [3], the vertical direction flux of a particle is not equal to zero in the channel used. There is, therefore, no permanent settling of particles in the middle of the channel, particles in other words being suspended in the middle region of the channel. According to the experimental results of Jha [14], a maximum concentration of particles on the bed does not significantly affect the mean velocities and the distribution of particle concentration. It does, however, affect turbulent kinetic energy. We can therefore still argue that cuttings on the bed may not have a significant effect on open channel flow depth and velocities.

\section{Conclusion}

Drilling well return flow is a multiphase non-Newtonian flow of mainly drilling mud and drill cuttings. The effect of drill cuttings on open channel flow was studied, with the results being presented in this paper. This can be used for well return flow estimation. The multifluid VOF model 3D CFD simulations were carried out for drilling fluid flow with drill cuttings in open channels. The CFD model was validated using experiment results published in the literature. The effect of drill cutting size on flow depth was found to be small compared to the effect of the cuttings fraction. The drill cuttings volume fraction doubled from $5 \%$ to $10 \%$ in open channel flow, with the average variation of the flow depth 
being $2.5 \%$. The effect of cuttings on flow depth in well return flow modeling for a short, prismatic (constant cross section) open channel was found to be small. The conclusion might be different for long and nonprismatic channels. The increase in particle friction due to the rise of the total particle volume is also small, and energy loss is negligible. The liquid level decreases for a higher solid fraction. Higher concentration acts as a higher net density. Thus, the higher density and approximately the same friction will yield a lower flow depth.

\section{Nomenclature}

$\begin{array}{ll}\vec{F}_{\text {lift,q }}: & \text { Lift force of } q \text { phase }(N) \\ \vec{F}_{\mathrm{Vm}, q}: & \text { Virtual mass force of } q \text { phase }(N) \\ g: & \text { Gravity vector }\left(\mathrm{m} / \mathrm{s}^{2}\right) \text {, gas phase } \\ h: & \text { Flow depth }(\mathrm{m}) \\ k: & \text { Turbulence kinetic energy }\left(\mathrm{m}^{2} / \mathrm{s}^{2}\right) \\ l: & \text { Liquid phase } \\ P: & \text { Pressure shared by all phases }(\mathrm{Pa}) \\ s: & \text { Solid phase } \\ T_{\mathrm{g}}: & \text { Temperature of gas phase }(\mathrm{K}) \\ T_{1}: & \text { Temperature of liquid phase }(\mathrm{K}) \\ T_{\mathrm{s}}: & \text { Temperature of solid phase }(\mathrm{K}) \\ \vec{u}_{q}: & \text { Three-dimensional velocity components of } q \text { phase } \\ U: & \text { (m/s) } \\ \alpha_{q}: & \text { Average velocity (m/s) } \\ \alpha_{1}: & \text { Volume fraction of } q \text { phase } \\ \alpha_{\mathrm{g}}: & \text { Volume fraction of liquid phase } \\ \alpha_{\mathrm{s}}: & \text { Volume fraction of solid phase } \\ \beta_{q}: & \text { Interphase momentum exchange coefficient } \\ \varepsilon: & \text { Turbulence dissipation rate }\left(\mathrm{m}^{2} / \mathrm{s}^{3}\right) \\ \rho_{q}: & \text { Density of } q \text { phase }\left(\mathrm{kg} / \mathrm{m}^{3}\right) \\ \overline{\bar{\tau}}_{q}: & \text { Stress-strain tensor of } q \text { phase }(\mathrm{Pa}) .\end{array}$

\section{Data Availability}

The CFD and experiment data used to support the findings of this study are included within the article.

\section{Conflicts of Interest}

The authors declare that they have no conflicts of interest.

\section{Acknowledgments}

The economic support provided by the Research Council of Norway and Equinor ASA through project no. 255348/E30 "Sensors and models for improved kick/loss detection in drilling (Semi-kidd)" is gratefully acknowledged. The authors thank Per Morten Hansen and Andre Vagner Gaathaug for their assistance.

\section{References}

[1] P. Welahettige, K. Vaagsaether, and B. Lie, "A solution method for one-dimensional shallow water equations using flux limiter centered scheme for open Venturi channels," The Journal of Computational Multiphase Flows, vol. 10, no. 4, pp. 228-238, 2018.
[2] S. K. Jha and F. A. Bombardelli, "Theoretical/numerical model for the transport of non-uniform suspended sediment in open channels," Advances in Water Resources, vol. 34, no. 5, pp. 577-591, 2011.

[3] K. T. Kiger and C. Pan, "Suspension and turbulence modification effects of solid particulates on a horizontal turbulent channel flow," Journal of Turbulence, vol. 3, p. N19, 2002.

[4] M. Muste, K. Yu, I. Fujita, and R. Ettema, "Two-phase flow insights into open-channel flows with suspended particles of different densities," Environmental Fluid Mechanics, vol. 9, no. 2, pp. 161-186, 2009.

[5] R. B. Spelay, "Solids transport in laminar, open channel flow of non-Newtonian slurries," Doctoral dissertation, The University of Saskatchewan, Saskatoon, Canada, 2007.

[6] S. Akhshik, M. Behzad, and M. Rajabi, "CFD-DEM simulation of the hole cleaning process in a deviated well drilling: the effects of particle shape," Particuology, vol. 25, pp. 72-82, 2016.

[7] B. Amanna and M. R. Khorsand Movaghar, "Cuttings transport behavior in directional drilling using computational fluid dynamics (CFD)," Journal of Natural Gas Science and Engineering, vol. 34, pp. 670-679, 2016.

[8] T. N. Ofei, S. Irawan, and W. Pao, "CFD method for predicting annular pressure losses and cuttings concentration in eccentric horizontal wells," Journal of Petroleum Engineering, vol. 2014, Article ID 486423, 16 pages, 2014.

[9] E. I. Epelle and D. I. Gerogiorgis, "A multiparametric CFD analysis of multiphase annular flows for oil and gas drilling applications," Computers \& Chemical Engineering, vol. 106, pp. 645-661, 2017.

[10] O. Heydari, E. Sahraei, and P. Skalle, "Investigating the impact of drillpipe's rotation and eccentricity on cuttings transport phenomenon in various horizontal annuluses using computational fluid dynamics (CFD)," Journal of Petroleum Science and Engineering, vol. 156, pp. 801-813, 2017.

[11] B. Pang, S. Wang, Q. Wang et al., "Numerical prediction of cuttings transport behavior in well drilling using kinetic theory of granular flow," Journal of Petroleum Science and Engineering, vol. 161, pp. 190-203, 2018.

[12] B. Pang, S. Wang, G. Liu, X. Jiang, H. Lu, and Z. Li, "Numerical prediction of flow behavior of cuttings carried by Herschel-Bulkley fluids in horizontal well using kinetic theory of granular flow," Powder Technology, vol. 329, pp. 386-398, 2018.

[13] Y. Ignatenko, O. Bocharov, A. Gavrilov, and R. May, "Steadystate cuttings transport simulation in horizontal borehole annulus," in Proceedings of the ASME 2018 37th International Conference on Ocean, Offshore and Arctic Engineering, Madrid, Spain, June 2018.

[14] S. K. Jha, "Effect of particle inertia on the transport of particleladen open channel flow," European Journal of Mechanics - B/ Fluids, vol. 62, pp. 32-41, 2017.

[15] R. S. Sanders, J. Schaan, R. G. Gillies et al., "Solids transport in laminar open-channel flow of non-Newtonian slurries," in Proceedings of the Hydrotransport, 15th International Conference, Incorporating the 11th International Symposium of Freight Pipelines, pp. 597-611, BHR Group, Cranfield, UK, June 2002.

[16] J. M. Treinen, "Modelling transport and deposition of coarse particles in viscoplastic tailings beach flows," Doctoral dissertation, University of Colorado, Boulder, CO, USA, 2017.

[17] A. M. Talmon, L. Sittoni, E. Meshkati Shahmirzadi, and J. L. J. Hanssen, "Shear settling in laminar open channel flow: analytical solution, measurements and numerical simulation," 
in Proceedings of the 21st International Seminar on Paste and Thickened Tailings, R. J. Jewell and A. B. Fourie, Eds., pp. 181-194, Australian Centre for Geomechanics, Perth, Australia, July 2018.

[18] J. M. Neff, "Fate and effects of water based drilling muds and cuttings in cold water environments," Report to Shell Exploration and Production Company, Neff \& Associates LLC, Houston, TX, USA, 2010.

[19] R. J. S. Pigott, "Mud flow in drilling," in Drilling and Production Practice, American Petroleum Institute, Washington, DC, USA, 1941.

[20] S.-M. Han, Y.-K. Hwang, N.-S. Woo, and Y.-J. Kim, "Solidliquid hydrodynamics in a slim hole drilling annulus," Journal of Petroleum Science and Engineering, vol. 70, no. 3-4, pp. 308-319, 2010.

[21] W. K. H. Ariyarathna, P. Welahettige, and M. C. Melaaen, "A parametric study for Euler-granular model in dilute phase vertical pneumatic conveying," International Journal of Computational Methods and Experimental Measurements, vol. 6, no. 1, pp. 46-58, 2018.

[22] B. N. Murthy, R. S. Ghadge, and J. B. Joshi, "CFD simulations of gas-liquid-solid stirred reactor: prediction of critical impeller speed for solid suspension," Chemical Engineering Science, vol. 62, no. 24, pp. 7184-7195, 2007.

[23] S. Akhshik, M. Behzad, and M. Rajabi, "CFD-DEM approach to investigate the effect of drill pipe rotation on cuttings transport behavior," Journal of Petroleum Science and Engineering, vol. 127, pp. 229-244, 2015.

[24] Z. Naumann and L. Schiller, "A drag coefficient correlation," Zeitschrift des Vereins Deutscher Ingenieure, vol. 77, pp. 318-323, 1935.

[25] D. Gidaspow, Multiphase Flow and Fluidization: Continuum and Kinetic Theory Descriptions, Academic Press, San Diego, CA, USA, 1994.

[26] ANSYS Fluent, 12.0 Theory Guide, ANSYS, Inc., Canonsburg, PA, USA, 2009.

[27] H. K. Versteeg and W. Malalasekera, An Introduction to Computational Fluid Dynamics: The Finite Volume Method, Pearson Education Ltd., Harlow, UK, 2nd edition, 2007.

[28] V. C. Kelessidis, R. Maglione, C. Tsamantaki, and Y. Aspirtakis, "Optimal determination of rheological parameters for Herschel-Bulkley drilling fluids and impact on pressure drop, velocity profiles and penetration rates during drilling," Journal of Petroleum Science and Engineering, vol. 53, no. 3-4, pp. 203-224, 2006.

[29] R. Haldenwang, Flow of Non-Newtonian Fluids in Open Channels, Cape Technikon, Cape Town, South Africa, 2003. 


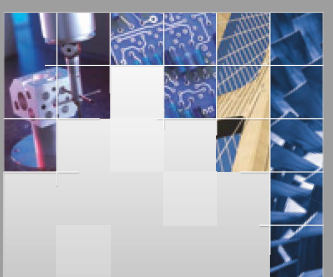

\section{Enfincering}
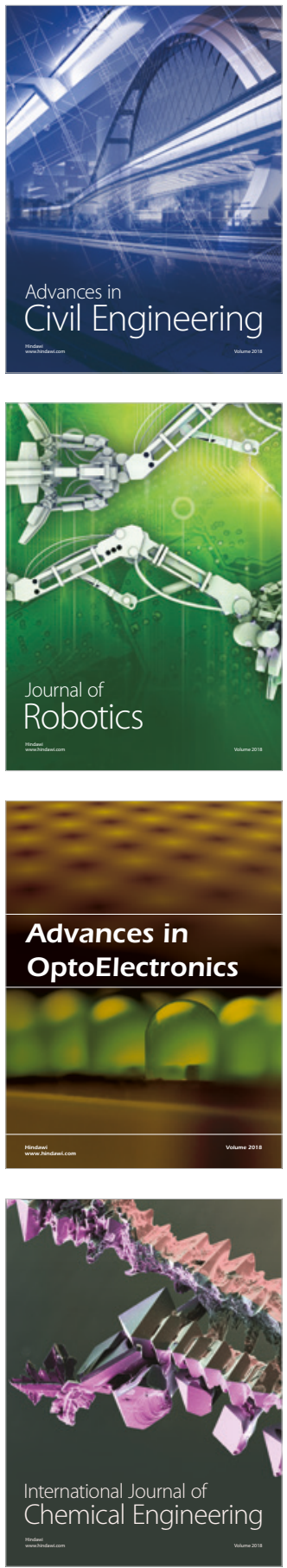

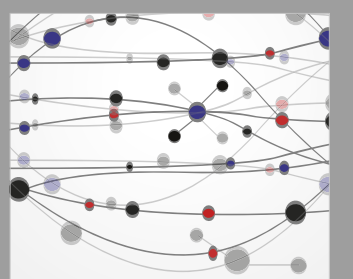

\section{Rotating \\ Machinery}

The Scientific World Journal

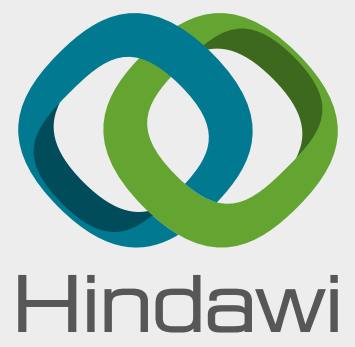

Submit your manuscripts at

www.hindawi.com
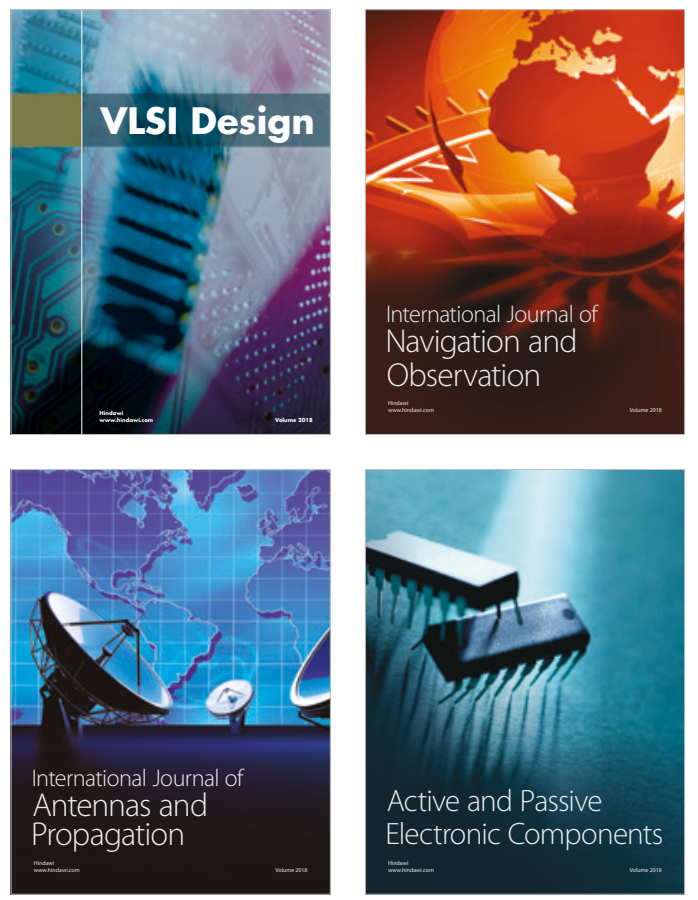
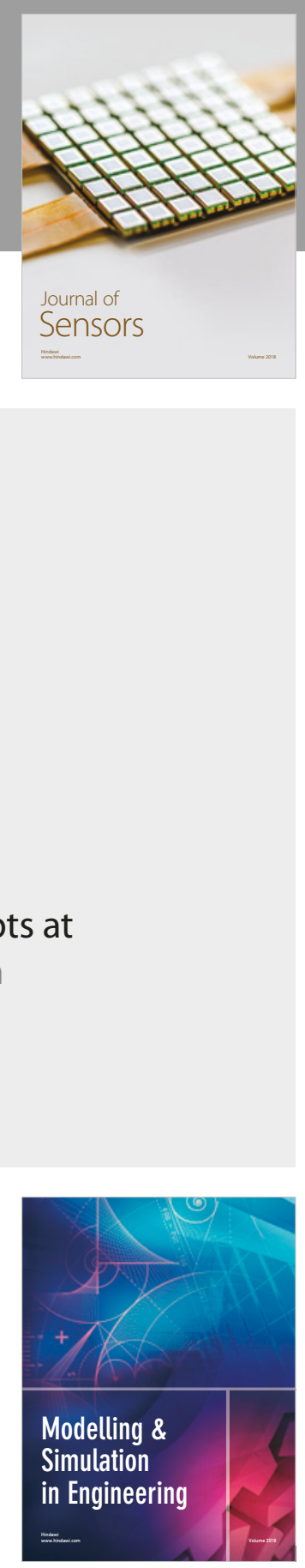

\section{Advances \\ Multimedia}
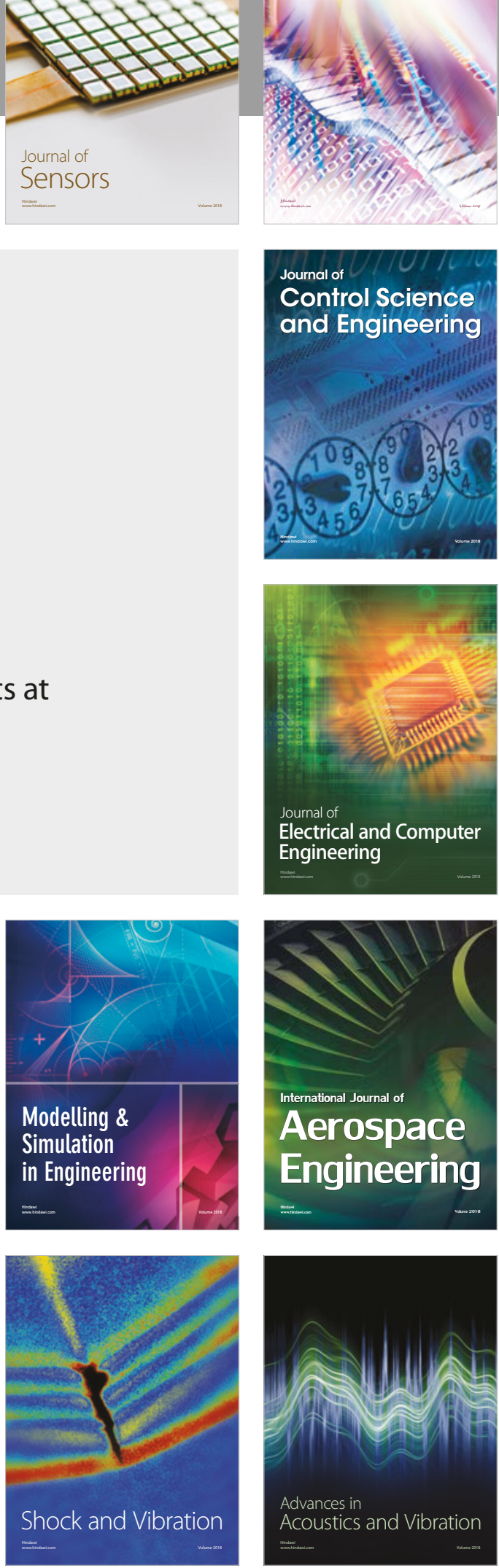